\title{
Moderate-to-vigorous physically active academic lessons and academic engagement in children with and without a social disadvantage: a within subject experimental design
}

Marijke J Mullender-Wijnsma ${ }^{1 *}$, Esther Hartman', Johannes W de Greeff ${ }^{1}$, Roel J Bosker ${ }^{2,3}$, Simone Doolaard ${ }^{2,3}$ and Chris Visscher ${ }^{1}$

\begin{abstract}
Background: Integration of physical active academic lessons in the school curriculum may be an innovative way to improve academic outcomes. This study examined the effect of physically active academic lessons (Fit en Vaardig op school) on academic engagement of socially disadvantaged children and children without this disadvantage. In addition, the relationship between lesson time spent in moderate to vigorous physical activity and academic engagement was examined.
\end{abstract}

Methods: From four elementary schools, 86 children who participated in the 22-weeks intervention were recruited (23 socially disadvantaged children). Academic engagement was determined by observing time-on-task during three classroom observation moments (start, midway and end observation). Every moment consisted of lesson observations after intervention lessons (post-intervention) and after regular classroom lessons (post-control). Differences in time-on-task between socially disadvantaged children and children without this disadvantage were analyzed using independent samples t-test. Differences between post-intervention and post-control observations were analyzed using multilevel analysis. Heart rate monitors measured the lesson time spent in moderate to vigorous physical activity. The relationship between percentage of moderate to vigorous physical activity during the intervention lessons and time-on-task was analyzed by calculation of partial correlations.

Results: Time-on-task of socially disadvantaged children was lower than that of children without this disadvantage, differences were significant at the start post-control $(t(65)=2.39, p<0.05)$ and post-intervention $(t(71)=2.75, p<0.05)$ observation and at the midway post-control $(t(68)=2.45, \mathrm{p}<0.05)$ observation. Multilevel analysis showed that the time-on-task of all children was significantly higher during post-intervention in comparison with post-control lessons $(E S=0.41)$. No significant difference was found at the start observation, but there were significant differences at the midway ( $E S=0.60)$ and end $(E S=0.59)$ observation. On average, the children were exercising in moderate to vigorous physical activity during $60 \%$ of de lesson time (14 minutes of an average lesson of 23 minutes). No significant relationships were found between percentage of moderate to vigorous physical activity during the intervention and time-on-task in the post-intervention lessons.

Conclusions: Physically active academic lessons may positively influence time-on-task in children, which can contribute to academic success in the long term.

\footnotetext{
*Correspondence: m.j.mullender-wijnsma@umcg.nl

'University of Groningen, University Medical Center Groningen, Center for Human Movement Sciences, Antonius Deusinglaan 1, Groningen 9713 AV The Netherlands

Full list of author information is available at the end of the article
}

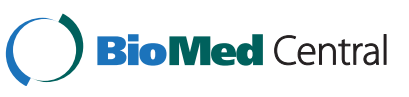

(c) 2015 Mullender-Wijnsma et al.; licensee BioMed Central. This is an Open Access article distributed under the terms of the Creative Commons Attribution License (http://creativecommons.org/licenses/by/4.0), which permits unrestricted use, distribution, and reproduction in any medium, provided the original work is properly credited. The Creative Commons Public Domain Dedication waiver (http://creativecommons.org/publicdomain/zero/1.0/) applies to the data made available in this article, unless otherwise stated. 


\section{Background}

Children who experience risk factors in their home environment, such as low parental education levels and low family income, are more likely to have poor academic outcomes [1]. One of the predictors of academic outcomes is academic engagement in the classroom, which can be measured by the time spent focusing on academic tasks (time-on-task) [2,3]. Because academic engagement of children during a school day is positively related to academic success, it is important for schools to make effective use of official school time and ensure that children's time-on-task is as high as possible [4]. Some studies showed that children from disadvantaged backgrounds have more difficulties with academic engagement. For example, children at-risk showed deficiencies in focusing on task in comparison with other children [5]. Interventions aimed at increasing academic engagement of children at-risk may contribute to the academic outcomes of these children [6].

A few studies showed positive effects of physically active academic lessons on time-on-task in subsequent regular classroom lessons. In one study effects were examined of short classroom-based physical activities (Energizers) that encourage children to move during academic instruction [7]. Third and fourth grade children showed a significant improvement in on-task behavior immediately after the Energizers. Another study explored the impact of the TAKE 10! program, in which movement and learning are integrated [8]. They found a reduction in off-task behavior of more than $20 \%$ after a physically active lesson and concluded that the active academic lessons had a positive effect on elementary school children's behavior in class. Furthermore, the Texas I-CAN physically active academic lessons were found to prevent the reduction in time-ontask experienced after a period of inactivity in elementary school children [9]. In addition, positive effects of a threeyear physically active academic intervention were found on academic achievement [10]. Although no time-on-task was measured in this study, the effects on academic achievement may, in part, be due to the effects on timeon-task.

To improve academic outcomes in children, physical activity of moderate to vigorous intensity (MVPA) during the lessons seems important $[10,11]$. This type of physical activity is linked with a substantial number of health benefits in children [12] and an increase of cerebral blood flow, which improves the oxygenation of the prefrontal cortex, a brain region that is important for cognitive functioning [13]. In addition, it stimulates immediate chemical changes in the brain, like increases in levels of dopamine and norepinephrine. These increased concentrations may immediately enhance attention and aid cognitive performance [14]. The question rises whether the lesson time spent in MVPA during physically active academic lessons influences the on-task behavior of the children immediately after the lessons. A study examined the short-term effects of moderate physical activity in children in an experimental setting. Primary school children walked on a treadmill at $60 \%$ of their estimated maximum heart rate for 20 minutes. After this exercise an improvement in attention and academic achievement was found [15]. Another study examined the time spent in the target heart rate zone $(55 \%-80 \%$ of their maximum heart rate) and its relationship to cognitive tasks. No evidence was found that time within the target heart rate zone was related to cognitive performance. However, the results suggested that vigorous activities (time spent above the target heart rate zone) might have cognitive benefits [16]. Although this study suggested effects of vigorous activities, a review study showed that MVPA could facilitate cognition and that intense exercise could be detrimental to cognition [17].

Summarized, in the literature we found an increase in time-on-task after physically active academic lessons and physical activity of moderate to vigorous intensity seems to be an important prerequisite in order to find positive effects. This study focuses on socially disadvantaged children (SDC) in the Netherlands, based on parental education level, who academically underperform in comparison with children without this disadvantage (non-SDC) [18]. The first aim of the present study was to confirm that SDC were less on task during regular classroom lessons in comparison with non-SDC. The second aim was to investigate the effect of 'Fit \& Vaardig op school' (F\&V; Fit and academically proficient at school), physically active academic lessons, on the time-on-task of SDC and non-SDC immediately after F\&V lessons. As it has been shown in the literature that disadvantaged children had poorer abilities to maintain their task attention [5], and that physical activity might be more effective for the attention of lower performers [19], it is hypothesized that SDC could benefit more from physically active academic lessons in comparison with non-SDC. The third aim was to examine if the lesson time spent in MVPA during the F\&V lessons was related to the time-on-task in the lessons that immediately followed the F\&V lessons. It was hypothesized that the more lesson time was spent in MVPA, the higher the time-on-task after the lesson. Highly intensive exercise was expected to be detrimental to cognitive performance [17].

\section{Methods}

\section{Participants}

As a part of the larger F\&V intervention, 86 elementary children (23 SDC) from second or third grade classes of four elementary schools from the Northern Netherlands were recruited to participate in this study. All children participated in the F\&V lessons. Any missing demographic 
information eliminated a child from all comparisons, resulting in a final sample of 81 children (mean age: $8.2 \pm$ 0.65 years; 41 girls; 40 boys). Children were classified as SDC or non-SDC based on parental education, children of whom the person(s) responsible for the daily care completed less than three years of secondary school were classified as SDC. In the context of the Dutch educational policy schools are required to obtain this data from every child. Based on this data, schools receive extra funds for SDC in their student population [20]. The SDC $(n=20)$ and non-SDC $(n=61)$ classification data were obtained from the personal school files of the children. Table 1 shows the demographic information of the children, it can be found that there were significantly more SDC in grade 2 in comparison with grade $3(p<0.05)$. A subgroup of 67 children (mean age: $8.2 \pm 0.59$ years; 33 girls; 34 boys; 15 SDC) wore heart rate monitors during the F\&V intervention. Written informed consent was obtained from the school principals of the participating schools. The parents/legal guardians were informed before the start of the intervention and were given the option to withdraw their permission for their child to participate at any time. Furthermore, the parents/legal guardians gave written informed consent for wearing heart rate monitors during the physical active academic intervention. All procedures were approved by the ethical committee of the Center for Human Movement Sciences of the University Medical Center Groningen/University of Groningen.

\section{Intervention}

The F\&V intervention consisted of physical active mathematics and language lessons that were taught in the classroom. The main (long-term) goal of F\&V was to improve academic skills and physical fitness of SDC and non-SDC. Children participated in the F\&V program for 22 weeks, three times a week. During each lesson the children stood behind or beside their school desk. In each lesson 10-15 minutes were spent on mathematics and 10-15 minutes on language. The main focus was on reinforced concepts learned in earlier classes. The physical exercises were relatively easy to perform and aimed at exercising at moderate to vigorous intensity level. During the lessons all children performed basic exercises and specific exercises simultaneously. The specific exercises were performed when the

Table 1 Participant demographics

\begin{tabular}{llll}
\hline & SDC $(\mathbf{n}=\mathbf{2 0})$ & Non-SDC $(\mathbf{n}=\mathbf{6 1})$ & $\boldsymbol{p}$ value \\
\hline Age, years (sd) & $8.3(0.8)$ & $8.2(0.6)$ & ${ }^{\mathrm{a}} 0.71$ \\
Gender, n boys (\%) & $10(50.0)$ & $30(49.2)$ & ${ }^{\mathrm{b}} 0.95$ \\
Second grade, n (\%) & $14(70.0)$ & $26(42.6)$ & ${ }^{\mathrm{b}} 0.03$ \\
BMl, $\mathrm{kg} / \mathrm{m}^{2}(\mathrm{sd})$ & $17.7(3.4)$ & $17.3(3.0)$ & ${ }^{\mathrm{a}} 0.61$ \\
Shuttle Run score $(\mathrm{sd})$ & $3.9(1.6)$ & $4.0(1.6)$ & ${ }^{\mathrm{a}} 0.78$
\end{tabular}

${ }^{\mathrm{a}}$ Independent t-test. ${ }^{\mathrm{b}} \mathrm{Chi}$-square test. children solved an academic task. For example, the word 'dog' must be spelled by jumping in place for every mentioned letter or the children had to jump 6 times to solve the multiplication ' $2 \times 3$ '. Similar academic tasks with different words or sums were exercised during one lesson. The basic exercises were performed during the remaining part of the lesson (for example when the children were thinking about a sum). Basic exercises were for instance, marching, jogging or hopping in place. A more complete description of the intervention and its implementation has been published elsewhere [21].

\section{Design and procedure}

In this study a within-subject design was used to determine whether physically active F\&V lessons affected the time-on-task in the regular classroom lessons that immediately followed the F\&V lessons. To do this, the time-on-task during a regular classroom lesson that followed a F\&V lesson (post-intervention) was compared to the time-on-task during a regular classroom lesson that followed a regular inactive lesson (post-control). On every participating school post-intervention and postcontrol observations took place at the start, midway and the end of the 22-week F\&V intervention period (see Table 2). In order to improve the reliability of the taskobservations, at the start and midway observation two post-intervention and two post-control observations were performed on every school in one week. At the end observation, one post-intervention and one post-control observation was performed on every school in one week. On each school, the post-intervention and post-control lessons were observed at different schooldays at about the same time of day (always before lunch time). A postintervention observation was followed by a post-control observation in the same week. All observations started when the regular classroom lesson, in which the children returned to their academic content, began. To assess the intensity of the $F \& V$ lessons, part of the children wore heart rate monitors during each physically active $F \& V$ lesson that was followed by observations.

\section{Time-on-task observations}

The time-on-task of the children was observed through time sampling, by using a modified version of the observation method described by Grieco et al. [9]. Every child was observed for the duration of five seconds, before the observer moved on to the next child. To support the observer an audio file was played through a headphone with beeps with an interval of five seconds. When every child was observed once, the observers started with the first child again and repeated this sequence for the remaining part of the lesson. We aimed at observing each child 15 times a lesson (50 minutes of observations in an average class of 20 children), this criteria was not 
Table 2 Design of time-on-task (ToT) observations and heart rate measurements during the lessons

\begin{tabular}{|c|c|c|c|c|c|}
\hline \multicolumn{2}{|l|}{ Start } & \multicolumn{2}{|l|}{ Midway } & \multicolumn{2}{|l|}{ End } \\
\hline Lesson & ToT observation & Lesson & ToT observation & Lesson & ToT observation \\
\hline 1.1 F\&V lesson* & Post-intervention & 2.1 F\&V lesson* & Post-intervention & 3.1 F\&V lesson* & Post-intervention \\
\hline 1.2 Regular lesson & Post-control & 2.2 Regular lesson & Post-control & & \\
\hline 1.3 F\&V lesson* & Post-intervention & 2.3 F\&V lesson* & Post-intervention & 3.2 Regular lesson & Post-control \\
\hline 1.4 Regular lesson & Post-control & 2.4 Regular lesson & Post-control & & \\
\hline
\end{tabular}

${ }^{*}$ Heart rate measurements were performed.

always met due to lesson interruptions (for example recess or lunch break). Eventually each child was observed 10-16 times a lesson. It was observed if a child showed on-task or off-task behavior. On-task behavior was defined as any behavior in which a child was attentive to the academic instruction or actively engaged in the appropriate task, as assigned by the teacher. All behaviors that were not on-task were noted as off-task behavior. Off-task behavior included fidget and listless behavior, for example wiggling on the chair, needless moving without paying attention, placing the head on the desk, talking to or looking at other children. During the start observation the inter-rater reliability of the observation method was determined. Five lessons were observed by two observers, the inter-rater reliability appeared to be of substantial agreement $[22,23], \mathrm{k}=0.73$.

\section{Assessment of lesson intensity}

Prior to the F\&V intervention a maximal endurance test (20 m Shuttle Run test) was performed during a physical education class. This test is an item of the Eurofit and consisted of running back and forward over 20 meter at an increasing speed [24]. Heart rate data were collected using team heart rate monitors [25]. The heart rate monitors averaged and stored heart rate every second throughout the test time. The maximum heart rate (HRmax) was determined by visual inspection of the heart rate curve that was obtained from the test.

Heart rate data were also collected during the F\&V lessons. Exercising with heart rates between $60 \%$ and 90\% of HRmax was considered as MVPA. Exercising above $90 \%$ of HRmax was considered as highly intensive exercise [26,27]. From the heart rate data, the lesson time spent in MVPA was calculated for each child for every observed F\&V lesson.

\section{Data analysis}

The percentages of time-on-task were calculated for each child by dividing the number of observations in which the child performed on-task behavior, by the total number of observations during that lesson. Next, the two post-intervention and two post-control observations that were performed at the start were merged into one post-intervention and one post-control observation by calculating the mean time-on-task. The same merging took place for the midway observation. The time in certain heart rate zones was calculated $(0-60 \%, 60-90 \%$ and $90-100 \%$ of HRmax) per child per lesson. By dividing the lesson time spent in $60-90 \%$ of HRmax with the total lesson time, the percentage of MVPA per child per F\&V lesson was calculated. Pearson's correlations were calculated between time-on-task, percentage of MVPA and participant demographics in order to detect important covariates. Demographics that significantly correlated with time-on-task or percentage of MVPA were used as covariates in further analyses.

Differences in time-on-task between SDC and non-SDC during post-control and post-intervention lessons (aim 1) were analyzed using independent samples t-tests (SPSS, version 20.0). Differences between post-intervention and post-control observations (aim 2) were analyzed using multilevel modeling (MLwiN 2.29). Time was nested within children and each individual had six observations. Multilevel models were calculated for the time-on-task of the children. The first model contained only the important covariates. Next, condition (post-intervention and postcontrol; model 2), the interaction between condition and SDC (model 3) and the interaction between condition and observation moment (model 4) were entered as possible predictors. Variables with a nonsignificant contribution to the model were removed from further analysis. Effect sizes were calculated as (mean post-intervention - mean postcontrol)/(pooled SD) [28,29].

The relationship between percentage of MVPA during F\&V lessons and time-on-task was analyzed by calculation of partial correlations controlling for the effect of important covariates (SPSS, version 20.0). Statistical significance for all analyzes was set at 0.05 .

\section{Results}

\section{Descriptive statistics}

Table 3 shows correlations between children's time-ontask, MVPA and their demographic variables. No significant correlations were found with gender. Four significant correlations were found between time-on-task and grade, two between MVPA and grade. Three significant correlations were found between time-on-task and BMI, two between time-on-task and the Shuttle Run Test score and 
Table 3 Correlations between children's time-on-task (ToT), MVPA and participant demographics

\begin{tabular}{|c|c|c|c|c|c|c|}
\hline & & Gender & Grade & BMI & Shuttle run & SDC \\
\hline \multirow[t]{4}{*}{ Start } & ToT Post-Intervention & -0.04 & $0.43^{*}$ & -0.08 & 0.07 & $-0.31^{*}$ \\
\hline & ToT Post-Control & -0.15 & 0.12 & -0.01 & 0.00 & $-0.28^{*}$ \\
\hline & MVPA 1.1 & 0.08 & $0.32^{*}$ & -0.01 & 0.08 & -0.20 \\
\hline & MVPA 1.3 & 0.03 & 0.10 & 0.03 & -0.10 & -0.12 \\
\hline \multirow[t]{4}{*}{ Midway } & ToT Post-Intervention & -0.17 & $0.35^{*}$ & $-0.29^{*}$ & $0.30^{*}$ & -0.16 \\
\hline & ToT Post Control & -0.15 & 0.18 & $-0.34^{*}$ & 0.22 & $-0.29 *$ \\
\hline & MVPA 2.1 & 0.04 & -0.05 & 0.11 & -0.20 & -0.08 \\
\hline & MVPA 2.3 & -0.02 & 0.15 & 0.09 & -0.15 & -0.05 \\
\hline \multirow[t]{3}{*}{ End } & ToT Post-Intervention & -0.04 & $0.26^{*}$ & $-0.33^{*}$ & $0.32^{*}$ & -0.15 \\
\hline & ToT Post-Control & 0.02 & $0.26^{*}$ & -0.13 & 0.19 & -0.13 \\
\hline & MVPA 3.1 & -0.04 & $-0.38^{*}$ & 0.09 & -0.21 & -0.11 \\
\hline
\end{tabular}

*Significant correlation (significance was set at 0.05 ).

three between time-on-task and SDC. The correlations indicated that third grade children and children with a high score on the Shuttle Run Test were more on task and that SDC and children with high BMI were less on task. Third grade children spent more time in MVPA.

\section{Time-on-task}

\section{Time-on-task differences between SDC and non-SDC}

Some children were absent during the start, midway and/ or end observation. In case of absence during the lessons for more than 50 percent, children were excluded from all analyses. Common reasons for missed observations were absence from school or doing schoolwork outside the classroom. Figure 1 shows that the time-on-task of SDC was lower than that of non-SDC during the post-control and during post-intervention lessons. Differences were significant at the start post-control $(\mathrm{t}(65)=2.39, \mathrm{p}<0.05)$ and post-intervention $(\mathrm{t}(71)=2.75, \mathrm{p}<0.05)$ observation and at the midway post-control $(\mathrm{t}(68)=2.45, \mathrm{p}<0.05)$ observation. No significant differences were found at the end observation.

\section{Time-on-task differences between post-intervention and post-control}

Table 4 shows the mean percentages of on-task behavior during intervention and control situations for SDC and non-SDC. The mean time-on-task of all children ranged from $88.1-92.1 \%$ during post-intervention lessons and 82.3-87.9\% during post-control lessons.

Table 5 displays the results of the multilevel analysis predicting children's time-on-task. The effect of the covariate Shuttle Run score was not significant $(p=0.33)$, so higher or lower fit children did not differ on their time-on-task, this variable was removed from further analysis. Model 1 shows a significant effect of the covariates grade, BMI, SDC and observation moment on children's time-on-task. Children in third grade were more on task and SDC and children with high BMI were less

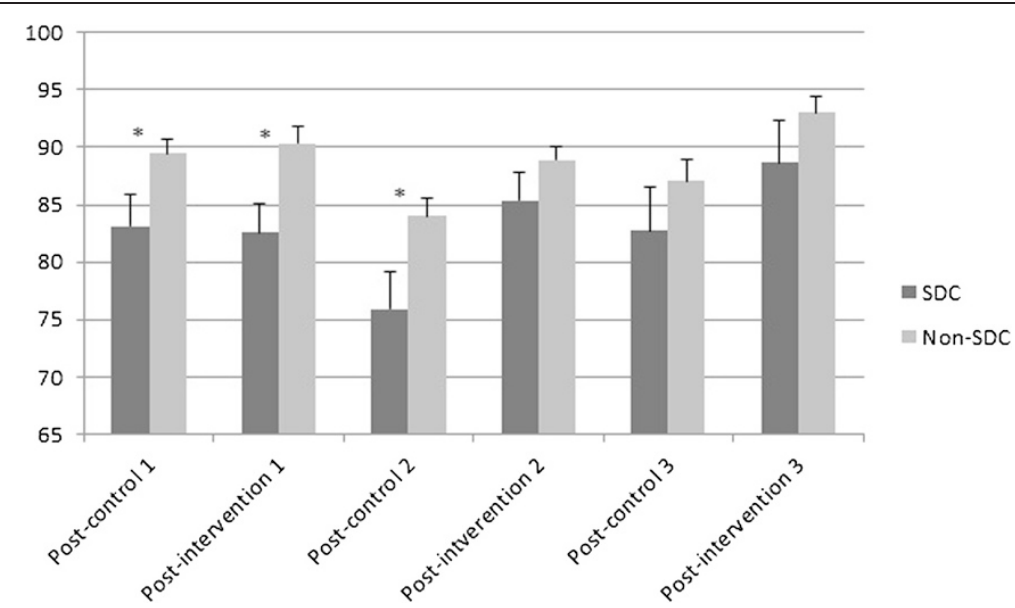

Figure 1 Mean percentages time-on-task with standard error bars of SDC and non-SDC during post-control and post-intervention lessons at start (1), midway (2) and end (3) observation. *Significant difference between SDC and non-SDC $(p<0.05)$. 
Table 4 Mean percentage time-on-task (SD); $\mathbf{n}$ during start, midway and end observation period

\begin{tabular}{lllll}
\hline & Observation & SDC & Non-SDC & Total \\
\hline Start & Post-Intervention* & $82.6(11.1) ; 19$ & $90.4(10.6) ; 54$ & $88.4(11.2) ; 73$ \\
& Post-control* & $83.1(11.6) ; 17$ & $89.5(8.7) ; 50$ & $87.9(9.8) ; 67$ \\
Midway & Post-Intervention* & $85.4(10.3) ; 18$ & $88.9(9.1) ; 58$ & $88.1(9.4) ; 76$ \\
& Post-control* & $75.9(12.4) ; 15$ & $84.0(11.0) ; 55$ & $82.3(11.7) ; 70$ \\
End & Post-Intervention & $88.7(13.9) ; 15$ & $93.0(11.2) ; 57$ & $92.1(11.8) ; 72$ \\
& Post-control & $82.7(14.5) ; 15$ & $87.1(14.2) ; 61$ & $86.2(14.3) ; 76$ \\
\hline
\end{tabular}

*Time-on-task of the two merged observations was not significantly different.

on task. In addition, the on-task behavior of all children was lower at the midway observation moment in comparison with the start observation. The second model indicates a significant effect of condition (post-intervention or post-control) on time-on-task favoring the post-intervention condition $(\mathrm{p}<0.05 ; \mathrm{ES}=0.41)$. This model was an improvement of the first model $\left(\Delta \mathrm{X}^{2}(1)=\right.$ $17.6, \mathrm{p}<0.05)$. Inserting the interaction between SDC and condition (model 3) did not significantly improve the model $\left(\Delta x^{2}(1)=0.1, p=0.75\right)$. As no significant interaction effect was found (the intervention did not affect SDC and non-SDC differently), the interaction was removed from the model. In the final model (model 4) the interaction between observation moment and condition was inserted. The model was significantly improved by this insertion $\left(\Delta x^{2}(2)=7.2, p<0.05\right)$ in comparison with the second model. No significant effect of condition was found during the start observation $(E S=0.04)$. The significant interaction effects between condition and midway observation and condition and end observation indicated a significant effect of condition during the midway (ES = $0.60)$ and end $(E S=0.59)$ observation compared with the start observation.

\section{Lesson intensity}

Time in MVPA and time-on-task

For the analyses of the association between time-on-task and time in MVPA, children who were absent during the Shuttle Run test were excluded. Table 6 shows that the number of children per observation moment ranged from 38 to 59. Mean percentages of MVPA during F\&V lessons ranged from $47-62 \%$ in SDC and $51-68 \%$ in nonSDC. The standard deviations were relatively large. On average, the children were exercising in MVPA during $60 \%$ of de lesson time, which is in accordance with 14 minutes of MVPA during an average F\&V lesson of 23 minutes. During on average 39\% of the lesson time the children were exercising at a low intensity level $(<60 \%$ of HRmax) and in on average $1 \%$ of the lesson time the children were exercising at a high intensity level

Table 5 Multilevel regression coefficients (B) and Standard Error (SE) for each factor predicting time-on-task

\begin{tabular}{|c|c|c|c|c|c|c|c|c|c|c|c|c|}
\hline & \multicolumn{3}{|c|}{ Model 1} & \multicolumn{3}{|c|}{ Model 2} & \multicolumn{3}{|c|}{ Model 3} & \multicolumn{3}{|c|}{ Model 4} \\
\hline & $B$ & $S E$ & $p$ & $B$ & $S E$ & $p$ & $B$ & $S E$ & $p$ & $B$ & $S E$ & $p$ \\
\hline \multicolumn{13}{|l|}{ Fixed effects } \\
\hline Random intercept & 96.18 & 5.39 & & 97.37 & 4.18 & & 97.45 & 4.19 & & 99.21 & 4.24 & \\
\hline Grade $^{a}$ & 4.98 & 1.34 & 0.00 & 4.97 & 1.34 & 0.00 & 4.97 & 1.34 & 0.00 & 5.02 & 1.34 & 0.00 \\
\hline BMI & -0.75 & 0.22 & 0.00 & -0.75 & 0.23 & 0.00 & -0.75 & 0.23 & 0.00 & -0.74 & 0.23 & 0.00 \\
\hline $\mathrm{SDC}^{\mathrm{b}}$ & -4.47 & 1.58 & 0.00 & -4.57 & 1.57 & 0.00 & -4.95 & 1.99 & 0.01 & -4.58 & 1.57 & 0.00 \\
\hline Midway observation $^{c}$ & -2.90 & 1.25 & 0.02 & -2.87 & 1.22 & 0.02 & -2.88 & 1.22 & 0.02 & -5.81 & 1.74 & 0.00 \\
\hline End observation ${ }^{c}$ & 0.51 & 1.25 & 0.68 & 0.67 & 1.22 & 0.58 & 0.67 & 1.22 & 0.58 & -2.17 & 1.71 & 0.11 \\
\hline Condition $^{d}$ & & & & 4.19 & 0.99 & 0.00 & 4.02 & 1.13 & 0.00 & 0.40 & 1.72 & 0.82 \\
\hline Condition*SDC & & & & & & & 0.71 & 2.34 & 0.76 & & & \\
\hline Condition*midway & & & & & & & & & & 5.63 & 2.41 & 0.02 \\
\hline Condition*end & & & & & & & & & & 5.54 & 2.40 & 0.02 \\
\hline \multicolumn{13}{|l|}{ Random effects } \\
\hline Variance between students & 12.57 & 5.40 & 0.02 & 13.28 & 5.35 & 0.01 & 13.32 & 5.36 & 0.01 & 13.70 & 5.35 & 0.01 \\
\hline Variance within students & 108.39 & 8.21 & 0.00 & 103.24 & 7.82 & 0.00 & 103.18 & 7.81 & 0.00 & 101.14 & 7.66 & 0.00 \\
\hline Deviance & 3250.83 & & & 3233.27 & & & 3233.18 & & & 3225.25 & & \\
\hline
\end{tabular}

$\overline{a, b, c, d}$ Respectively second grade, non-SDC, start observation and control condition were the reference categories. 
Table 6 Mean percentages MVPA per observation moment (SD); $\mathbf{n}$, and partial correlations of MVPA with time-on-task

\begin{tabular}{|c|c|c|c|c|c|}
\hline & \multicolumn{2}{|l|}{ Start } & \multicolumn{2}{|l|}{ Midway } & \multirow{2}{*}{$\begin{array}{l}\text { End } \\
\text { Lesson } 3.1\end{array}$} \\
\hline & Lesson 1.1 & Lesson 1.3 & Lesson $2.1^{*}$ & Lesson 2.3 & \\
\hline \multirow[t]{2}{*}{ SDC } & $55.3(28.1) ; 14$ & $60.0(26.6) ; 15$ & 56.6(33.3); 11 & $47.2(31.3) ; 14$ & $61.7(31.9) ; 12$ \\
\hline & $r=0.08$ & $r=0.09$ & $r=0.14$ & $r=-0.01$ & $r=0.15$ \\
\hline \multirow[t]{2}{*}{ non-SDC } & $68.0(26.7) ; 44$ & $67.3(26.1) ; 44$ & $62.2(33.0) ; 27$ & $51.1(34.3) ; 45$ & $52.4(35.2) ; 42$ \\
\hline & $r=-0.03$ & $r=0.08$ & $r=0.11$ & $r=0.17$ & $r=-0.15$ \\
\hline \multirow[t]{2}{*}{ Total } & $65.0(27.4) ; 58$ & $65.5(26.2) ; 59$ & $60.5(32.7) ; 38$ & $50.2(33.4) ; 59$ & $54.5(34.4) ; 54$ \\
\hline & $r=0.03$ & $r=0.09$ & $r=0.11$ & $r=0.16$ & $r=-0.07$ \\
\hline
\end{tabular}

*Heart rate measurements of one school were missing because of technical errors.

(>90\% of HRmax). In both SDC and non-SDC no significant correlations (while controlling for grade) were found between the percentage of MVPA during a F\&V lesson and the time-on-task in the regular classroom lesson that immediately followed the F\&V lesson (Table 6).

As the children were hardly exercising at a high intensity level ( $>90 \%$ of HRmax), it was not possible to calculate correlations between the percentage of highly intensive exercise and time-on-task.

\section{Discussion}

The present study showed significantly lower time-on-task in SDC compared with non-SDC during regular classroom lessons. Time-on-task of both SDC and non-SDC was significantly higher during post-intervention than postcontrol lessons, indicating that the time-on-task of both groups may have benefited from the F\&V lessons. In both groups there was no significant relationship between the percentage of MVPA during F\&V lessons and time-ontask in the regular classroom lessons that immediately followed the F\&V lessons.

\section{Time-on-task}

The results showed that during regular classroom lessons, the on-task behavior of SDC was significant lower than the on-task behavior of non-SDC. It is well known that SDC academically achieve less than non-SDC [18], but less is known about the discrepancy in on-task behavior. Given the discrepancy that was found in the current study, focusing on the on-task behavior of SDC might contribute positively to academic success in the long term. Previous research showed that physically active academic lessons positively influenced children's time-on-task in regular classroom lessons that followed [7-9]. The present study demonstrated that the F\&V intervention was beneficial to the on-task behavior of both SDC and non-SDC. The intervention lessons did not affect the on-task behavior of SDC and non-SDC differently. Future research should further investigate whether or not in the long term the academic performance of SDC and non-SDC also benefit from the F\&V intervention.
After F\&V lessons the time-on-task of all children was significantly higher than the time-on-task after regular control lessons. Only the start observation did not show a significant difference between post-intervention and post-control lessons. It is possible that during the first post-intervention observations, the children had to get used to the observers and, as a consequence, were less on-task. But the argument could also be used reversed. It is possible that the children were more on-task during the first control lessons because they saw the researchers for the first time.

In this study academic engagement was measured by observing children's time-on-task. It can be discussed whether or not time-on-task observation is an adequate method for measuring academic engagement. According to Johnson et al. [30] academic engagement refers to, inter alia, making an effort to learn, completing homework, coming to class and being attentive in class. Although time-on-task observations do not cover all these components of academic engagement, several studies have demonstrated that time-on-task (as a measure of academic engagement) was positively related to academic achievement $[3,31]$.

\section{Lesson intensity}

In the current study we found that the children showed MVPA in on average $60 \%$ of the lesson time (in accordance with 14 minutes of an average 23 minutes $F \& V$ lesson). To our knowledge, this study was the first to assess the amount of MVPA of physically active academic lessons through heart rate measurements. Other studies used other instruments to assess MVPA, i.e. accelerometers [32,33] or indirect calorimeters [33], and also showed that the physical activity level of physically active academic lessons was mainly MVPA. The present study extends these findings by investigating the relationship between MVPA and time-on-task.

As the children were hardly exercising at a high intensity level it was not possible to draw any conclusions about highly intensive exercise. The results demonstrated that the percentage of time in MVPA during F\&V lessons was not related to the time-on-task in the lessons that 
immediately followed the F\&V lessons. These results were similar for both SDC and non-SDC. The standard deviations showed that differences between children in the amount of lesson time spent in MVPA were large. So, some children were exercising in MVPA during the whole lesson time, while others were exercising at lower intensity levels. Apparently, more lesson time spent in MVPA during $F \& V$ lessons does not automatically lead to a higher percentage of time-on-task in the subsequent regular classroom lesson. These findings are in accordance with a previous study, in which no significant relationship between the time spent in the target heart rate zone (55-80\% of HRmax) and cognitive performance was found [16]. It could be possible that not only MVPA, but also the change of sedentary classroom time into another activity (F\&V lesson) may facilitate the on-task behavior in the subsequent regular classroom lesson. This is in accordance with studies that investigated the effect of recess breaks with time for free play. During recess breaks some children were physically active while others were spending their time standing in small groups, talking. These studies found that children were more on task, less fidget and behaving better in class when they had a break [34,35].

Physically active academic classroom lessons might have additional benefits. For example, because the lessons generate mainly MVPA, positive effects on academic performances as well as physical fitness are expected [36]. Furthermore, Best [14] suggests that an interaction between aerobic physical activity and cognitive engagement may have a stronger effect on cognitive functioning. Moreover, the physically active academic lessons save time because the extra physical activity does not come at the expense of academic instruction. In order to further investigate the additional benefits of moderate-to-vigorous physically active academic lessons on cognitive functioning and physical fitness future research is necessary.

\section{Limitations}

This study has some limitations. First, although a binary classification of socioeconomic status is commonly used in the literature [37], it may partly account for the limited effects found between SDC and non-SDC in the current study. The advantage of using the current classification is that it can be obtained from the personal school files of the children. Secondly, the missing heart rate data at one time point could have influenced the results. However, as the findings at this time point are similar to the findings at the other four time points, we assume that the results were hardly influenced. Third, the small sample sizes (of mainly the SDC group) could have influenced the results and conclusions. Future research with a larger sample size is warranted to examine whether or not the lower on-task behavior of SDC is consistent and to further investigate the influence of physical active academic lessons on the on-task behavior of SDC.

\section{Conclusions}

The on-task behavior of socially disadvantaged children was lower than that of children without this disadvantage during regular classroom lessons. Physically active academic F\&V lessons may positively contribute to the time-on-task of socially disadvantaged children as well as children without this disadvantage. The F\&V lessons generated moderate to vigorous physical activity in on average $60 \%$ of the lesson time and may therefore be beneficial to children's health. However, no significant relationship was demonstrated between the physical intensity of the F\&V lessons and time-on-task in the subsequent regular classroom lessons. The findings suggest that physically active academic lessons may be an innovative way for teachers to increase children's academic engagement and physical activity without losing time intended for academic learning.

\section{Abbreviations}

MVPA: Moderate to vigorous physical activity; SDC: Socially disadvantaged children; non-SDC: Children without a social disadvantage; F\&V: Fit \& Vaardig op school (Fit and academically proficient at school); HRmax: Maximum heart rate.

\section{Competing interests}

The authors declare that they have no competing interests.

\section{Authors' contributions}

MJM contributed to the design, acquisition of the data, analysis of the data and helped drafted manuscript. EH, JWG, RJB, SD and CV participated in the design, analysis of the data, drafting and critical review of the manuscript. All authors read and approved the final manuscript.

\section{Acknowledgements}

This work was supported by the Ministry of Education, Culture and Science [ODB10015]. The authors wish to acknowledge Rik Poelarends for his help in the completion of this manuscript and the intervention teachers and children at the participating schools for their cooperation in this study.

\section{Author details}

${ }^{1}$ University of Groningen, University Medical Center Groningen, Center for Human Movement Sciences, Antonius Deusinglaan 1, Groningen 9713 AV The Netherlands. ${ }^{2}$ University of Groningen, Groningen Institute for Educational Research, Grote Rozenstraat 3, Groningen 9712 TG, The Netherlands. ${ }^{3}$ University of Groningen, Faculty of Behavioral and Social Sciences, Department of Educational Sciences, Grote Rozenstraat 3, Groningen, 9712 TG, The Netherlands.

Received: 15 December 2014 Accepted: 10 April 2015 Published online: 19 April 2015

\section{References}

1. Sirin SR. Socioeconomic status and academic achievement: a meta-analytic review of research. Rev Educ Res. 2005;75:417-53.

2. Greenwood CR, Horton BT. Academic engagement: current perspectives in research and practice. School Psych Rev. 2002;31:328-49.

3. Wyne MD, Stuck GB. Time-on-task and reading performance in underachieving children. J Reading Behav. 1979;11:119-28.

4. Scheerens J, Hendriks M, Luyten $H$, Sleegers $P$, Glas C. Productive time in education, a review of the effectiveness of teaching time at school, homework and extended time outside school hours. Den Haag: NWO; 2013. 
5. Howse RB, Lange G, Farran DC, Boyles CD. Motivation and self-regulation as predictors of achievement in economically disadvantaged young children. J Exp Educ. 2003;71:151-74.

6. Sektnan M, McClelland MM, Acock A, Morrison FJ. Relations between early family risk, children's behavioral regulation and academic achievement. Early Child Res Q. 2010:25:464-79.

7. Mahar MT, Murphy SK, Rowe DA, Golden J, Shields AT, Raedeke TD. Effects of a classroom-based program on physical activity and on-task behavior. Med Sci Sport Exerc. 2006;38:2086-94.

8. Kibbe DL, Hackett J, Hurley M, McFarland A, Schubert KG, Schultz A, et al. Ten years of TAKE 10!: integrating physical activity with academic concepts in elementary school classrooms. Prev Med. 2011;52:S43-50.

9. Grieco LA, Jowers EM, Bartholomew JB. Physically active academic lessons and time on task: the moderating effect of body mass index. Med Sci Sport Exerc. 2009;41:1921-6.

10. Donnelly JE, Lambourne K. Classroom-based physical activity, cognition, and academic achievement. Prev Med. 2011;52:S36-42.

11. Coe DP, Pivarnik JM, Womack CJ, Reeves MJ, Malina RM. Effect of physical education and activity levels on academic achievement in children. Med Sci Sports Exerc. 2006;38:1515-9.

12. Strong WB, Malina RM, Blimkie CJ, Daniels SR, Dishman RK, Gutin B, et al. Evidence based physical activity for school-age youth. J Pediatr. 2005:146:732-7.

13. Timinkul A, Kato M, Omori T, Deocaris CC, Ito A, Kizuka T, et al. Enhancing effect of cerebral blood volume by mild exercise in healthy young men: a near-infrared spectroscopy study. Neurosci Res. 2008;61:242-8.

14. Best JR. Effects of physical activity on children's executive function: contributions of experimental research on aerobic exercise. Dev Rev. 2010;30:331-51.

15. Hillman $\mathrm{CH}$, Pontifex MB, Raine LB, Castelli DM, Hall EE, Kramer AF. The effect of acute treadmill walking on cognitive control and academic achievement in preadolescent children. Neuroscience. 2009;159:1044-54.

16. Castelli DM, Hillman $\mathrm{CH}$, Hirsch J, Hiersch A, Drollette E. FIT Kids: time in target heart zone and cognitive performance. Prev Med. 2011;52:S55-9.

17. Tomporowski PD. Effects of acute bouts of exercise on cognition. Acta Psychol. 2003;112:297-324.

18. Driessen $\mathrm{G}$, Dekkers H. Dutch policies on socio-economic and ethnic inequality in education. Int Soc Sci J. 2009;59:449-64.

19. Drollette ES, Scudder MR, Raine LB, Moore RD, Saliba BJ, Pontifex MB, et al. Acute exercise facilitates brain function and cognition in children who need it most: an ERP study of individual differences in inhibitory control capacity. Dev Cogn Neurosci. 2014;7:53-64.

20. Ministry of Education, Culture and Science. Brochure nieuwe gewichtenregeling basisonderwijs. Zoetermeer: CFI; 2006 [http://www.rijksoverheid.nl/documenten-en-publicaties/rapporten/ 2006/04/26/nieuwe-gewichtenregeling-basisonderwijs.html].

21. Mullender-Wijnsma MJ, Hartman E, de Greeff JW, Bosker RJ, Doolaard S, Visscher C. Improving academic performance of school-age children by physical activity in the classroom: 1-year program evaluation. J Sch Health. 2015:85:365-71.

22. Cohen J. A coefficient of agreement for nominal scales. Educ Psychol Meas. 1960:20:37-46.

23. Viera AJ, Garrett JM. Understanding interobserver agreement: the Kappa Statistic. Fam Med. 2005:37:360-3.

24. Council of Europe. Testing physical fitness: Eurofit experimental battery. Provisional handbook. Strasbourg: Council of Europe; 1983.

25. Polar. Team2 SW help, user's guide. Kempele: Polar Electro Oy; 2008.

26. American College of Sports Medicine. Position Stand. The recommended quantity and quality of exercise for developing and maintaining cardiorespiratory and muscular fitness, and flexibility in healthy adults. Med Sci Sport Exerc. 1998;30:975-91.

27. Howley ET. Type of activity: resistance, aerobic and leisure versus occupational physical activity. Med Sci Sport Exerc. 2001;33:S364-9.

28. Glass GV, McGaw B, Smith ML. Meta-analysis in social research. Beverly Hills: Sage Publications; 1981

29. Tymms P, Merrell C, Henderson B. The first year at school: a quantitative investigation of the attainment and progress of pupils. Educ Res Eval. 1997;3:101-18.

30. Johnson MK, Crosnoe R, Elder GH. Students attachment and academic engagement: the role of race and ethnicity. Sociol Educ. 2001;74:318-40.
31. de Jong R, Westerhof KJ, Kruiter JH. Empirical evidence of a comprehensive model of school effectiveness: a multilevel study in mathematics in the 1st year of junior general education in the Netherlands. Sch Eff Sch Improv. 2004;15:3-31.

32. Stewart JA, Dennison DA, Kohl HW, Doyle JA. Exercise level and energy expenditure in the TAKE 10! In-class physical activity program. J School Health. 2004;74:397-400.

33. Honas JJ, Washburn RA, Smith BK, Greene JL, Donnelly JE. Energy expenditure of the physical activity across the curriculum intervention. Med Sci Sports Exerc. 2008:40:1501-5.

34. Barros RM, Silver EJ, Stein REK. School recess and group classroom behavior. Pediatrics. 2009;123:431-6.

35. Jarrett OS, Maxwell DM, Dickerson C, Hoge P, Davies G, Yetley A. Impact of recess on classroom behavior: group effects and individual differences. J Educ Res. 1998;92:121-6.

36. Hillman $\mathrm{CH}$, Castelli DM, Buck SM. Aerobic fitness and neurocognitive function in healthy preadolescent children. Med Sci Sport Exerc. 2005;37:1967-74

37. Chomitz VR, Slining MS, McGowan RJ, Mitchell SE, Dawson GF, Hacker KA. Is there a relationship between physical fitness and academic achievement? Positive results from public school children in the Northeastern United States. J Sch Health. 2009:79:30-7.

\section{Submit your next manuscript to BioMed Central and take full advantage of:}

- Convenient online submission

- Thorough peer review

- No space constraints or color figure charges

- Immediate publication on acceptance

- Inclusion in PubMed, CAS, Scopus and Google Scholar

- Research which is freely available for redistribution

Submit your manuscript at www.biomedcentral.com/submit 